\title{
State: Typological Analysis of Evolutionary Forms
}

\author{
Valentin Y. Lyubashits ${ }^{1}$ \\ Andrey Y. Mordovcev \\ Aleksey Y. Mamychev² \\ Maria V. Vronskaya² \\ ${ }^{1}$ Southern Federal University \\ 2 Vladivostok State University of Economics and Service \\ E-mail: kafedra_tgp@mail.ru
}

Doi:10.5901/mjss.2015.v6n3s4p83

\section{Abstract}

In this article, the authors propose a new approach to the concept and content of the typology of the state. In particular, draws attention to the fact that the historical-typological approach to the state assumes the need for genetic analysis, the learning of the state in a dynamic position, namely the permanent transition to the most advanced forms. It is known that Siberia initially had been inhabitated by Russian immigrants from North districts of European part of Moscow Rus - from Novgorod, Arckhagelsk, Vologda, Vyatka regions from Perm the Great. The Russian government also has an interesting and complex history in terms of formation and typology. (Karabulatova, Sayfulina, Ahmetova, 2013: 139). Organized settlement was followed by unauthorized inhabitation. Peasants went to Siberia not only forced by "pribor", order but independently secretly. This could not but affect the character of the evolution of statehood in Russia. Statehood in Russia is closely related to evolutionary processes in the personality of the Russians. As rightly emphasizes I.S. Karabulatova, "we see that the complexity of the process of cultural texts (which is most characteristic of the culture of the European type) has the character of entropy at observed primitivization forms, the abundance of a variety of" remakes ", typing motifs and images. Virtualization consciousness, provoking introvertiveness character development of the world, contributes to the design of new virtual cultural spaces with its internal logic and perception system para-reality, specific cultural codes and identification codes, their history and mythology" [Karabulatova, 2013: 794].

Keywords: state, historical type, form of state, socioeconomic structure, essence of state.

\section{Introduction}

The variety of states of different peoples and at different times implies similarity and repeatability of some traits they possess. Their generalization allows to combine considered social phenomenon in a single structure - type. On the other hand, the diversity of states determines also the presence of their specific characteristics, due to which they can be classified into different types. For example researchers of Russian-Kazakhstan near-border territories note that native speakers of Russian dialects of this zone retain the features of mother language and culture (Karabulatova, Sayfulina \& Ahmetova, 2013: 137).

The term "typology", introduced to the scientific by French scientist Blainville in 1816 (Gorodtsov, 1927, p. 3.), is widely used today in various fields of human knowledge: sociology, history, literature, linguistics, archaeology, jurisprudence, etc.

Historical-typological approach to the state captures our attention to its relatively stable intrinsic properties in a developed state. This implies the need for a genetic approach to the state, its knowledge in a dynamic state of origin, transition to the advanced forms, the death of this specific historical type of state and its replacement with other state of historical type.

In cognitive terms, the concept of historical type of state is the logical basis for the release of his General theory to the theory of certain types of state and to enter these theories in a General theory of the state as its elements. The typological approach to the state has the effect of his the learning types in the state of embeddedness in a broader comprehensive holistic education - culture, deterministic variety of internal and external factors: the improvement of technology, population growth, diminishing resources, etc. 


\section{Literature Review}

In science there are different approaches to the typology of the society and the state and the forms of their historical development. So, G. Jellinek bases the classification of states on their organization and functions, as well as from the nature of the relationship between the individual and the state. Guided by these features, Jellinek relates Oriental, Greek and Roman states to three different types of states (Jellinek, 1903, p. 22). In addition to these types, he highlights the medieval and the modern state (Jellinek, 1903, p. 186).

A similar classification of types of state gives Russian historian N. I. Karyev. He identifies six types of states: the state-city, Oriental despotism, manor, class monarchy, Western European absolute monarchy and a constitutional state (Karyev, 1905, p. 71).

Significant place in the typology of the state takes the theory of two main types of statehood: democracy and autocracy. For example, Gans Helsen believes that typification of the modern states must be based on the "ideas of political freedom" (Helsen, 1946, p. 284).

French author Raymond Aron also distinguishes between two main types of modern state system in whichever the governor is whether a multi-party or single-party system (Aron R., 1965, p . 234).

American Professor Maciver, in his turn, divides the state into two types: a) dynastic where the General will (the state) does not express the will of the majority of citizens, and b) democratic, in which the common will reflect the will of the whole society or the majority of it (Maciver, 1964, p. 342-343).

The most common criterion of typology of states, which is widely used in the framework of theory of state and other sciences, until recently was considered a socio-economic formation. It is a historical type of society based on a particular mode of production and acting as a critical stage in the progressive development of mankind.

Each socio-economic formation is characterized by a certain type of production relations. Each of them has, along with world history, their very own laws of occurrence and development. Over the economic basis of each socio-economic formation rises corresponding add-ons as a set of ideas, theories, beliefs, ideas, institutions, and agencies, and systems emerging relations between them. Each social class formation corresponds to a specific historical type of state. Changing from one socio-historical formations of the other marks the changing system of industrial relations - the economic base, emerging on the bases of add-ons, along with the appropriate type of state.

One of the most popular classifications of political forms belongs to the American researcher Elmano Servis. He first noted that presented by Oberg structural types, at the same time represent successive evolutionary stages. Servis has identified four historical types: local groups; tribe; chiefdom; early state. Already in an early state the central authority receives a monopoly on legitimate use of force. Namely here appears writing, civilization, cities. This scheme during the last three decades has repeatedly supplemented and specified.

Richard Adams, using a typology of Servis, looked at the evolution of forms of power as a sequential increase of control over the energy of society. He also proposed a global design that includes six levels of social integration: local groups; chiefdoms or province; state or Kingdom; national; international and world levels. An important addition was the splitting of these levels into two parallel flows - centralized and coordinated unit. So, on the third level in the category of centralized units are included the city-state and Kingdom, and in the group agreed units - alliances, religious associations, and the formation of the (Adams, 1975).

Equally important for the development of the theory of politogenesis was a discussion about the origin and nature of the state. In it active participated M. Fried and E. Servis. Fried, by the way, offered a different from Servis' typology: "egalitarian society - ranked society - stratified society - state" (Fried, 1967). Fried believed that the state arises as a result of conflict resolution in a stratified society. Servis insisted on that the formation of the state is connected with the necessity of integration, because it is complicating. Discussion on these issues is not ended, and its continuation is observed in the Russian science. Important is the inclusion in the national science of neoevolutionism theories "of chiefdoms and early states". It may include the concept of "power-property", developed by L.S. Vasiliev (Lubashic, Mordovtsev \& Mamishev, 2013).

It should be noted that recently in works on the theory of states there is a tendency to withdraw from the consideration of the historical types, for the reason that the basis of the typology is the Marxist doctrine of socialeconomic formations. However, as rightly noted by V. A. Rjevskiy, it is well known that in the process of historical development of society has never been a state at all, were only a particular state of a particular type (Rjevskiy, 1992, $p$. 13; \& Lubashic, Mordovcev \& Mamichev, 2010). 


\section{Methods and Materials}

The present study is based on a multidimensional, complex analysis at considering the evolution of the state and the allocation of specific, concrete historical types of the state. The typological approach to the state has the effect of learning of its types in the condition of embeddedness in a broader comprehensive holistic education - culture, deterministic variety of internal and external factors: the improvement of technology, population growth, diminishing resources, etc.

To classify the evolutionary form of the state is possible only on the basis of a number of theoretical and methodological principles. These include as a priority the principle of substantiality, taking into account the main characteristics that determine the quality of social regimes that specifies, in their turn, the specifics of the political and legal regimes.

The development of the concept of "mode ("human mode"), which is actively operated by Dutch scientists $Y$. Goudsblom and F. Speer, was continued by the Russian philosopher and political scientist N. Rozov, who identified four types of human modes corresponding to the four ontological spheres:

- eco-technological regimes (material aspects of human interaction with nature; demographic processes);

- $\quad$ mental modes (regular processes of the psyche and communication of individuals, groups, communities);

- social modes (regular military, political, economic, moral, legal and other interactions).

These theoretical and methodological foundations and principles appears as required in the analysis of the types and evolution of states.

\section{Results and Discussions}

On the background of the new quest of global socio-philosophical thought became apparent extremes and unilateralism of formational structure of society. These extremes become apparent: first, in the absolute economic basis of the structure of society; secondly, in the systemic underestimation of the value of the intangible economic factors, social structures, such as political, cultural, ethnic, etc.; thirdly, in the stiffness of information of the structural relationships, their weak variance with regard to specific circumstances and stages of development of historical periods, regions, countries; fourthly, in the tendency to "superimposition" of formational patterns on the characteristics of any given society, the adjustment of its features under formational scheme; fifthly, in excess, contrasting structural patterns as "correct" other models in the structure of society as idealistic and misguided (Gurevic, 1990).

As rightly noted by M.N. Marchenko, based on this criterion, it should not be absolutized and only the right should be considered, as a kind of "universal" criterion of typing of states. For, firstly, besides him, as it is known, there are other, albeit less General, criteria for the typing of the state, the integrated use of which helps to make a better, strictly a reasonable classification of the phenomena in question. And secondly, the criterion according to which the state is determined only by the material to a particular socio-economic structure, needs serious clarification. Because the world has always existed and there are many other so-called transition countries and legal systems that "do not fit" in the framework of one or another formation (General theory, 2001, p. 181).

There are numerous definitions of historical type of state, which are found in the scientific literature, especially political-legal, differ little from each other. "The type of state as approved in edition 1980, is called being under development and is ultimately founded in the nature of the economic system class society complex essential features, in which the state differs from the other states" (Theory of state and law, 1980, p. 78).

Similar definitions are characteristic of other publications (Theory of state and law, 1977), as well as monographs (Petrov, 1967, p. 21). "The type of state and law refers to a logical extent in the development of state and legal systems that exist within the same socio-economic structure, characterized by the unity of the economic base, class entity and external forms of existence" (Theory of state and law, 1987, p. 142). In relatively recent publications on the General theory of state and law the historical type of state is seen as a set of basic traits that are typical of states and legal systems of a certain socio-economic structure that expresses their class nature, content and social class assignment (General theory of state and law, 1996; Theory of state and law, 2000; \& Theory of state and law, 2007).

In addition, many definitions historical type of state is regarded as a number of characteristic features and peculiarities of the state. To determine and assign a state to a particular historical type, it is necessary to know its features and properties, however, the analysis of these traits in determining historical type turns them into self-sufficient magnitude, since they are detached from the phenomena, i.e. the state itself. Thus the historical type of state is deprived of the historical reality, as a separate structural integrity of education.

It should be noted that in the interpretation of historical type of state should be proceeded from the following: first, to recognize the importance and the necessity of determining the type of state; secondly, to recognize that the type is not 
of any separately existing state, and the scientific category, generalized existing on this historical period states and legal systems; thirdly, this category is not speculative, and is the sum of the most important, common to all these states and legal systems of signs and features and, fourthly, in the process of determining the type of state as based should be taken no formal legal but, above all, essential and substantial characteristics and traits.

The transition from one historical type of state to another is both revolutionary and evolutionary, in the process of transition changes the social purpose, and hence the essence of the state.

The formation of a new type of state occurs by the separation of individual states from the old type and attach them to a new, there is a single process of the struggle of the new with the old, gradually replacing the old with the new.

Today in the academic environment does not receive a distribution analysis of the evolution of society from the point of view of "progress". The review of the issues from the position of a qualitative reorganization of the company into another state in a neutral context complications of cultural forms is updated. In the theory of politogenesis certain popular possesses theoretical paradigm of neoevolutionism. A prominent spokesman is Julian Steward. He adhered to the theory of multi-linear evolution and on this basis showed a functional relationship between the environment that determines the evolutionary diversity of forms, and the level of technology and socio-political organization. The society, according to Steward passes successively eight stages - from hunting and gathering to an industrial society.

Ethnologist, Kalervo Oberg in 1955 proposed a typology of cultural forms based on differences of political structures. Obergovs' typology can be applied to cultures not only in South and Central America, but to other parts of the world. The typology was the following: 1) homogeneous tribes; 2) segmented tribes; 3) politically organized chiefdoms; 4) feudal state; 5) city-States; 6) a theocratic Empire (Oberg, 1955, p. 472-487).

We believe that belonging to state - organized society to a particular historical type should be determined on the basis of the analysis of its modes, aspects and elements of these modes.

Let's refer to the criteria, wearing integrative nature that will help to classify the evolutionary forms of the state. The parameters, variables, reflecting the complex characteristics with obvious "levels" can be selected. This will be the parameters or characteristics, certain changes of which make up the class or type of explained phenomena (dependent variables).

A set of dependent or explained variables at one stage of historical development sets its peculiar trend structure. If the variables are crossing the limits allotted to them, the previous trend-structure "ceases to be oneself" i.e. a phase transition or rise to a qualitatively different stage of development is taking place.

Classification of States according to historical types implies, in our opinion, subject to the following aspects (variables) of basic social modes:

- level of political evolution (the development of political structures and institutions);

- organization and scale of military force, the level of development of communication, such as transport, communication, monitoring tools;

- the level of development of self-production of weapons;

- the ability to create and maintain alliances (the level of development diplomacy) and to provide internal and external legitimization;

- $\quad$ the level of accumulation and development of knowledge and practices (Kononova \& Yakimova, 2013);

- the level of development of ways to meet the spiritual needs;

- the development of ways of acculturation (Kirsanova\& Korotina, 2014);

- the development of ways of reproduction (nature provide new cycles and new stages of production);

- $\quad$ the development of ways of redistribution and exchange (the order of meeting the needs in terms of economic and geographical diversity);

- $\quad$ the level of development of equipment and technology for peaceful area (Rozov, 2001).

Historical type of state can be formulated on the basis of characteristics at a paired basic parameters of social regimes (political-legal, economic and cultural).

Thus the historical type of state has a certain unity of basic social modes, including compulsory general political power, the mode of exchange and distribution of goods and services.

Ten of the above parameters, just set an ideal historical type of state. Each state corresponds to a certain degree of maturity on all ten parameters.

However, we highlight the level of political development as a universal significance. It can serve as the main criterion or factor for the fixation of transition from one historical type of state to another.

In other words, this criterion allows us to trace the evolutionary series in sequence from less developed and simple to the more complex and developed forms of political organization. In determining evolutionary row in the categories of increasing complexity we are aware that the process of change from simple to complex is not the essence of the cultural 
and political evolution. In this case, it is difficult to explain cyclical development and those cases where at different stages of evolution again appear similar political structures. Here it is useful to refer to the concept of structural changes. Evolution will be understood as "the process of structural reorganization in time, as a result of which occurs the form or structure which is qualitatively different from previous forms". (Voget, 1975, p. 862).

As an example, here is a table from the study of A.V. Korotaeva on the relationship between the type of economy and the level of political integration (Korotaeva, 1991, p. 141).

Table 1. The types of farming and the level of political development

\begin{tabular}{|c|c|c|c|c|}
\hline Index of statehood & A & B & C & Total \\
\hline 0 & 49 & 10 & 9 & 68 \\
\hline $1-4$ & 13 & 24 & 18 & 50 \\
\hline $5-7$ & 0 & 4 & 26 & 30 \\
\hline Total & 62 & 38 & 53 & 153 \\
\hline
\end{tabular}

A - appropriated economy, B - early agriculture, C - well developed agriculture;

0 - 7 «index of statehood» by George. Murdock, where in general: 0 - simple communities,

1 - 4 - society with well-developed internal structure and chiefdom, 5 - 7 - state formations of varying difficulty.

It is clearly seen that there is a positive relationship between the complexity of systems management and the growth of political centralization.

Obviously, the historical development of states went in different ways, but at the same time, it is, as rightly pointed out by Jonathan Haas, has "such important common features, as the nascent bureaucracy, the ruling elite, the state religion, the standing army and a centralized economy. These common features, expressing the essence of the state organization, occur in cultures that provide an answer to such similar forces, as population pressure, decreasing resources and increasing complexity of society" (Hass, 1995, p. 22).

A certain level of political evolution defines the boundary separating state formations of the same type from public entities of another type. The important point is to identify signs of determination through which the crossing of the border is carried out. So, A.V. Korotayeva determines the level of political evolution or the level of statehood by two parameters: the number nadobny of hierarchical levels and their development, as well as the specialization of the apparatus of coercion (Korotaeva, 1991, p. 136-191).

Carneiro calls the state the social structure with a government that can force people to work and war. Here we see two operational parameters: the presence/absence of the government and the ability/inability of the government to force people to work and war. Under this definition, the "presence/absence of government" will be the parameter or attribute, the change of which will make up the class or type explain phenomena (level political evolution).

Another researcher T. Skocpol determined basic transformation of the state through the implementation of classbased revolts from below, thereby highlighting three main parameters: the speed of transformation, its base or non-base character and the presence/absence of class-based revolts from below. Skocpol used as a dependent variable two of the three parameters - the second and third. In other words, the transformation of state structures and the presence of uprisings from below are the dependent variable for the re-interpretation of historical type of state.

Here is another example of determining the state belonging to Alf Ross. He believes that state action can speak intelligently in two cases: "when the action is the realization of a state authority or official powers of coercion" and "when the action is the execution of a certain work, paid from the state Treasury" (Ross Alf., 1960, p. 123-124). Ross leads the state's actions (the actions of man, as if they are proceeded from the state) by four points: this person wields power as holding a public office; his powers include the power to order others; these powers are not carried out for its own interests and in the interests of legal institutions for the common good; when these powers are intertwined with others, in the money making system of power (government). Here, as in the case of Carneiro, the most important parameter (dependent variable) is the presence of state power (apparatus of coercion), which is lawfully established for the public good (the second parameter).

Researchers differently determine the phase state of development of society (politogenesis) and properly interpret evolutionary forms (historical types) of state. We identify three such historical types:

- traditional state;

- feudal state;

- modern state.

The chiefdom represents a type of socio-political organization, which creates the preconditions for the transition 
from communal autonomy to the state. Therefore, the chiefdom we will also explore as independent historical type. In the Marxist-Leninist historiography not "chiefdom" but "military democracy" was seen as a form of social organization period of decomposition of the tribal system and the transition to the state.

In the same vein, on the basis of common economic base, a single class entity and uniform principles of organization and activity stood out of the state of classical types (slave, feudal, capitalist). Within these historical types statehood is stood out so-called subtypes. In the slave - Patriarchal-slave (statehood countries of the Ancient East) and antique (statehood Ancient Greece and Rome). In feudal feudal, caste, absolutist. In the bourgeois - industrial and imperialist.

All this means that the problem of the typology of the state is complex and not amenable to a single interpretation. Historical types of States and their political level can be expressed by the following examples.

Traditional state in its typological interpretation is characterized by the presence of petty despots, kingdoms, kingdoms, principalities ... By I. M. Dyakonov this type includes the State of Yin in China and all that preceded the Qin Empire until the III century BC; in Japan - all renegotation era until the Nara period (III-VI centuries BC); in Europe Creto-Mycenaean civilization of the second Millennium BC (and in the first Millennium BC - Etruscan); early States of the North and East, the Anglo-Saxon to the IX century ad; the Scandinavian and Slavic to XII century.; in Africa to the type of early ancient societies can be attributed to the state Malinke, Songhay VII-XV CC. BC, the state of the Hausa people with the X - XI centuries BC and the state of the Congo, of bunyoro and Buganda (XVIII century), etc. (Diakonov, 1994, p. 38).

In this state there is a centralized institution with official positions, which is not limited to kinship and military elite, and which is able to force people to work and war. There are also structures of power with a monopoly on legitimate violence in the territory. This type may have anti-state form, but nevertheless it is able to perform the basic functions of the state (the organization of military force, maintaining its legitimacy). Society of early statehood may be equal to each other.

The feudal state as a historical type of state includes various territorial Empire, the Principality and the Kingdom of the feudal structure, protocapitalist city-States. Examples of state entities of this type can serve as the Chinese Empire since the Han from the first century ad; the Empire in Japan XII-XVI centuries; the Mauryan state (IV-II century BC); The Byzantine Empire; the Achaemenid Empire of the Persians; the Empire of Charlemagne; the Mongolian nomadic Empire; Ottoman Empire; Muscovy XIV-XVI centuries; the colonial empires of Portugal and Spain, etc.

In the feudal state was systemized management of large territories. The Central bureaucracy was carried out by a variety of functional activities, concentrated in their hands the military, tribute, customs, judicial, partly ecclesiastical matters. However, dispersion or the dualism of political power: the power in the center and the individual power of the feudal lords, their estates and seniors is observed. On the local level, the power belonged to the rulers, bearing different names (king Basileus, Prince, Han, Lord, Baron, Mandarin, Bai, etc.), but performing essentially the same governmental functions.

The Code of General laws is formed, but local laws of the provinces and cities continued to play an important role.

The concept of the feudal state is associated primarily with the dominant forms of social and political organization of the European middle ages, with specific dependency relationships (Liege/vassal) based on the existence of fief supports this relationship.

The modern state typologically originates in the Netherlands since the end of XVI century, in England from the late XVII century, in France, Prussia in different measurement from the middle of XVIII - early XIX centuries., in most countries of Western Europe - where at the beginning, where since the mid XIX century., in Russia in different aspects from the beginning of the XVIII - beginning of XX centuries, Turkey, Japan since the late XIX century, in China, India, Brazil, most countries rest of the world since the mid- XX century the United States, Australia, Canada and others are modern States from the XVIII century. Today to this belong the vast numbers of states. Such state is also called national government.

Thanks to the principle of territorial organization of political power, centralization and institutionalization of political authority and monopoly on the legitimate use of force within the national society, the state was able to maintain the population and control the law and order, to build up their military capabilities and to conquer new territory, to support the civil loyalty and use advantages of the market economy.

\section{Conclusions}

The type is a scientific category, a collective image of the actually existing on this historical period states and legal systems. This category is the sum of the most important, common to all these states and legal systems of signs and features and in the process of determining the type of state as a basis should be taken not formal legal but, above all, 
essential and substantial characteristics and traits.

The transition from one historical type of state to another is both revolutionary and evolutionary, in the process of transition changes the social purpose, and hence the essence of the state. The formation of a new type of state occurs by the separation of individual states from the old type and attaching them to a new, there is a single process of the struggle of the new with the old, gradually replacing the old with the new.

Historical type of state can be formulated on the basis of characteristics of paired basic parameters of social regimes (political-legal, economic and cultural). Such signs include: the level of political evolution (the development of political structures and institutions); the level of organization and scale of military force, the level of development of communication, such as transport, communication, monitoring tools; the level of development of self-production of weapons; the ability to create and maintain alliances (the level of development diplomacy) and to provide internal and external legitimacy; the level of accumulation and development of knowledge and practices; the level of development of ways to meet the spiritual needs; development of methods of acculturation; the level of development of methods of reproduction (nature provide new cycles and new stages of production); the level of development of methods of redistribution and exchange (the order of meeting the needs in terms of economic and geographic diversity); the level of development of equipment and technology for peaceful area.

Clearly identified such phase state of development of society (politogenesis) and evolutionary forms (historical types) of states as: traditional state; the feudal state; the modern state.

There are four innovative stages in the legal institutionalization of modern political domination: civil state, the rule of law, democratic state of law and social state.

During the existence of legal, philosophical, and political science dozens of different theories and doctrines were created, so many attempts of evolutionary typology of forms of the state were made. Made Hundreds, if not thousands of contradictory assumptions were declared. However, arguments about the nature of the state, its essence and the conditions of occurrence continue to the present day. Theoretical difficulties were associated with the complexity and ambiguity of concrete historical processes of formation and development of the state.

\section{References}

Gorodtsov, V.A. (1927). The Typological method in archaeology. Ryazan. pp. 172.

Gurevich, A.J. (1990). The Theory of formations and the reality of history //Questions of philosophy. №11.pp.11-37.

Dyakonov, I.M. (1994). The paths of history. M. pp. 27-53.

Jellinek, G. (1903). The Right of the modern state. Vol. 1. The General doctrine about the state. SPb. pp.148.

Karabulatova, I.S. (2015). The problems of linguistic modeling of new Eurasian linguistic personality in multilinguistic and mental environment (by example of onomasphere). In the: Middle-East Journal of Scientific Research 17 (6). pp. 791-795.

Karabulatova, I.S., Sayfulina F.S. \& Ahmetova B.Z. (2013). Ethno-lingual aspect of modern functioning of Russian dialects in North Kazakhstan (on an example of Kostanai region). In the: World Applied Sciences Journal Issue 27 (Education, law, economics, language and communication). pp. 137-140.

Kareev, N.I. (1905). Typological and world-historical perspective in the study of history. /lin: proceedings of the St. Petersburg Polytechnic Institute (economic. DEP.). Vol. 3. Vol. 1-2. SPb. pp.93.

Korotayev, A.V. (1991). Some economic background of class formation and politogenesis/l Archaic society: key problems of the sociology of development. M. Part 1. pp.156-160.

Lubashic V.J., Mordovtsev A.Y. \& Mamichev A.Y. (2013). State power: paradigm, methodology and typology. M.

Lubsshic V.J., Mordovtsev A.Y \& Mamyshev A.Y. (2010). Theory of state and law. Rostov on Don. pp.502.

General theory of law and state, (1996). Edited by V.V. Lazarev. M., 1996.pp.472.

General theory of state and law, (2001). Academic course. Vol. 1 /Resp. editorship of Professor M.N. Marchenko. M. pp.123-154.

Petrov, V.S. (1967). The Type and form of the state. L. pp.140-142.

Rzhevskiy, V.A. (1992). Fundamentals of state and law. Rostov on Don. pp.48-61.

Rozov, N. (2001). Towards a reasonable periodization of world history //the Time in the world. Vol.2. Novosibirsk. pp. 449-461.

Theory of state and law (1977). Edited by A.M. Vasiliev. M. pp. 3-22.

Theory of state and law (1980). Edited by A.I. Denisov. M. pp.432. pp.616.

Theory of state and law (1987). Resp. edited by A. I. Korolev, L. S. Javic. 2nd ed. L. pp.20.

Theory of state and law (2000). Edited by Professor V.M. Karelskiy \& Professor V.D. Perevalov. M. pp.35-38.

Theory of state and law (2007). Under the editorship of prof. N.I. Matuzov \& Professor A.V. Malko. M., 2004. pp. 308.

Haas, J. (1995). The Road to statehood // Alternative ways of early statehood/ Resp. edited by I.N. Kradin \& V.A. Linsha. Vladivostok: Dalnauka. pp.19-22.

Adams, R.N. (1975). Energy and Structure. A Theory of Social Power. Austin. pp.33-35.

Aron, R. (1965). Democratie et Totalitarisme. Gallimard. pp.378.

Fried, M.H. (1967). The evolution of political society; An essay in political anthropology. New York: Random House. pp.713-731. 
Helsen, G. (1946). General Theory of Law and State. Cambridge. pp.746.

Kononova, O. \& Yakimova Z. (2013). Competence as an object for Assessmen and Measuremen in Training Quality Control System//World Applied Sciences journale. T.27. pp. 536-540.

Kirsanova, L., Korotina, O. (2014). On the Contents of the Protest Conscience in Russia. Wolrd Applied Sciences Journal 31(5). pp. 930934.

Maciver R. (1964) The Modern State. Oxford. pp.516.

Oberg, K. (1955). Types of Social Structure Among the Lowland Tribes of South and Central America // American Anthropologist. Vol. 57. pp. $472-487$

Ross, Alf. (1960). On the Concepts "State" and "State Organs" in Constitutional Low. Scandinavien Studies in Low. Vol. 5. pp.66-79.

Voget, F.W. (1975). A history of ethnology. N.Y.: Holt, Rinehart and Winston. pp.69-73. 